\title{
SURVEILLANCE OF HIV INFECTION AMONG PATIENTS WITH TUBERCULOSIS IN NEPAL
}

\author{
Sah SK ${ }^{1}$, Verma SC ${ }^{1}$, Bhattarai R $^{1}$, Bhandari $K^{2}$, Bhatta GK ${ }^{3}$ \\ ${ }^{1}$ National Tuberculosis Centre, Thimi, Bhaktapur, Nepal \\ ${ }^{2}$ National Centre for AIDS and STD control, Teku, Kathmandu, Nepal \\ ${ }^{3}$ SAARC Tuberculosis and HIVIAIDS Centre, Thimi, Bhaktapur, Nepal
}

\begin{abstract}
Introduction: Tuberculosis is one of the most prevalent infectious disease and significant public health problem in Nepal. The importance of HIV surveillance among tuberculosis (TB) patients is increasingly being recognized as the HIV epidemic continues to fuel the global TB epidemic. In many countries the HIV prevalence in TB patients is a sensitive indicator of the spread of HIV into the general population. The aim of this study is to find out the HIV epidemic among TB patients.
\end{abstract}

Methodology: This was a periodic sentinel survey, i.e. cross-sectional HIV Sero-prevalence survey of all newly registered TB cases above 15 year old to provide point estimate. This survey was carried out in six major diagnostic centres of tuberculosis of Nepal from July 2012 to February 2013. The calculated sample size for the surveillance study was 1000 . The findings were processed/analyzed using SPSS (version 16) computer software. Descriptive statistics was used to observe the pattern in each variable.

Results: The study revealed that four-fifth $(80.9 \%)$ TB patients investigated were pulmonary positive and one-fifth (19.1\%) extra pulmonary. Prevalence of HIV among tested TB patients was $2.4 \%$ and prevalence was comparatively more $(2.8 \%)$ in Male than Female (1.4\%). Sentinel site wise prevalence of HIV was higher (6.7\%) in United Mission to Nepal (UMN), Palpa followed by $3.1 \%, 2.9 \%$ and $2.7 \%$ in District Public Health Office (DPHO), Kanchanpur, International Nepal Fellowship (INF), Nepalgunj and Regional tuberculosis Centre (RTC), Pokhara respectively. Comparatively prevalence was low (1.3\%) in National Tuberculosis Centre (NTC), Thimi and not a single case of HIV among tested TB patients was found in Nepal Anti-TB Association (NATA), Biratnagar. Significant proportion (7.8\%) of HIV prevalence was found in the age group of $35-39$ years followed by $4.6 \%, 3.6 \%$ and $2.8 \%$ among the age group of 40-44 years, 50-54 years and 30-34 years age group respectively.

Conclusion: Among all TB/HIV co-infected, significant proportion is found in 35-39 years and lowest in 20-24 age group. Therefore, it is important to implement targeted interventions in the age group between 30-55 years age group. Provider Initiated Testing and Counseling (PITC) in TB clinical setting plays important role to enroll more TB patients for HIV test.

Key words: HIV clients, TB/HIV Co-infection, Pulmonary and Extra Pulmonary TB, ART, PITC

\section{INTRODUCTION}

Tuberculosis (TB) is one of the most prevalent infectious disease and significant public health

\section{Correspondence:}

Mr. Sujit Kumar Sah

TB/HIV Coordination Officer

National Tuberculosis Centre, Thimi, Bhaktapur,

E-mail: sujitmph12@gmail.com problem in Nepal and continues to pose serious threat to the health of the population and development of the country. Tuberculosis usually affects the lungs (Pulmonary TB) but it can also occur in other parts of the body (Extra-pulmonary TB). Every person who inhales the droplets will not develop TB disease unless his immunity status is poor. It is estimated that only $10 \%$ of infected people will develop the disease. Extra pulmonary $T B$ is virtually never infectious. 
WHO estimates prevalence of all types of tuberculosis cases for Nepal at 74,000 (223/100K) while the number of all forms of incidence cases is estimated around 50,000 (163/100K). With the introduction of Directly Observed Treatment Short course (DOTS) number of deaths has dramatically reduced from $9712(51 / 100 K)$ in 1990 to 6200 in $2010(21 / 100 K){ }^{1,2}$

The HIV pandemic presents a massive challenge to the control of TB at all levels. These two diseases are inextricably linked. There is an unprecedented scale of epidemic of HIV-related tuberculosis that demands effective and urgent action. TB is the leading cause of death among People Living with HIVIAIDS (PLWHA) and HIV, through immune suppression, fuels the TB epidemic. Currently, the most powerful risk factor for developing TB disease is HIV. After TB infection, a person with HIV have $10 \%$ annual risk and $60 \%$ life-time risk of developing TB disease, compared with a $10 \%$ life-time risk for person's without HIV. The HIV epidemic, therefore, creates a large pool of persons at high risk of developing TB and, as a result, increases the pool of persons who will ultimately develops TB and transmit TB to HIV-infected and HIV uninfected persons. HIV-infected patients can develop TB at any level of immune-suppression.,

Thus HIV prevention and care must be a priority concern for TB Prevention and Control Programmers and TB care and prevention should be a priority concern for HIVIAIDS Prevention and Control programmers. As the HIVIAIDS and TB epidemics have progressed, surveillance has become a critical activity in understanding the trends of the epidemics and in enabling sound strategies to be developed for responding to these challenges. Surveillance of HIV among TB patients is important as the HIV epidemic has continued to fuel the TB problem. Since 1996 NTP has conducted five rounds of HIV prevalence surveys among TB patients with two to three year interval. The first survey conducted in 1995/96 established HIV prevalence among TB patients at $0.60 \%$ while in the latest survey $(2006 / 07)$ this has risen to $2.40 \%$.

\section{METHODOLOGY}

This was a periodic sentinel sero-prevalence survey for measuring HIV prevalence among TB patients. This survey was carried out among all new smear positive, smear negative and extra pulmonary TB patients who were consenting and $>15$ year old. Survey was carried out in six major diagnostic centres of tuberculosis of Nepal from July 2012 to February 2013. None consenting and patients less than 15 year of age were excluded from the survey.

The calculated sample size for the surveillance study was 1,000. These 1000 samples were obtained from the 6 different diagnostic centers; samples were distributed according to prevailing workload of the selected sites. Consecutive sampling method were used i.e. every patient who met the eligibility criteria at a particular site was included in the survey until the required sample size was reached. All subjects was accessible to pre and post counseling and testing for HIV infection. All patient intended to take part in the survey signed a written consent form. All patient related information was decoded and personal information was kept confidential and secured.

Considering the sensitivity and specificity of HIV tests, NTP used blood testing to allow for a relatively high positive predictive value. NTP used National AIDS Programme/National Public Health Laboratory/MOHP recommended testing strategy for diagnosis of HIV.

Collected data were verified and coded daily after completing the activities. Prior to the data entry, data were cleaned with the consultation of concerned supervisor in the respective sites. During data processing, there were constant check for relevancy, consistency, and accuracy of the data sets. Data quality was monitored through periodic examination of each step in the collection, collation and analysis process.

Collected data were verified and coded with the consultation of concerned sentinel site's technical personnel. The findings were processed/analyzed using SPSS (version16) computer software to determine the distribution of and associations between key variables. Data were analyzed for each sentinel site and for defined age groups and gender. Descriptive statistics was also used to observe the pattern in each variable.

\section{RESULTS}

National Tuberculosis Centre has conducted the study in six sentinel sites with the objective 
to ascertain the prevalence of HIV among TB patients who were tested for HIV. Based upon the study conducted among 995 TB patients who were tested for HIV and analysis were performed accordingly as shown in below tables:

Table 1. Sentinel Sites and Sex wise distribution of TB patients $(\mathrm{N}=995)$

\begin{tabular}{|l|c|c|c|c|}
\hline Sentinel Sites & $\begin{array}{c}\text { Male } \\
(\%)\end{array}$ & $\begin{array}{c}\text { Female } \\
(\%)\end{array}$ & No & $\%$ \\
\hline $\begin{array}{l}\text { NATA } \\
\text { Biratnagar }\end{array}$ & 74.6 & 25.4 & 134 & 13.5 \\
\hline NTC Thimi & 74.8 & 25.2 & 305 & 30.7 \\
\hline RTC Pokhara & 68.3 & 31.7 & 186 & 18.7 \\
\hline UMN Palpa & 67.6 & 32.4 & 105 & 10.6 \\
\hline INF Nepalgunj & 82.7 & 17.3 & 104 & 10.5 \\
\hline $\begin{array}{l}\text { DPHO } \\
\text { Kanchanpur }\end{array}$ & 64.6 & 35.4 & 161 & 16.2 \\
\hline Total & $\mathbf{7 2}$ & $\mathbf{2 8}$ & $\mathbf{9 9 5}$ & 100 \\
\hline
\end{tabular}

The above table 1 analyzes the facility and sex wise distribution of the TB patients. Out of the total TB patients, the higher percent $(30.7 \%)$ were from NTC Thimi followed by RTC Pokhara (18.7\%) and DPHO Kanchanpur (16.2\%). In all six sentinel sites, among the total male TB patients visited, higher percentage was found in INF Nepalgunj $(82.7 \%)$ and lowest male TB patients' percent was seen in DPHO Kanchanpur. Among the female TB patients, highest percent visited was found in DPHO Kanchanpur and lowest percent was in INF Nepalgunj (17.3\%)

\begin{tabular}{|l|c|c|c|c|}
\hline \multicolumn{6}{|c|}{ Table 2. Age Group distribution of TB patients } \\
\hline Age group & Male (\%) & Female (\%) & No & $\%$ \\
\hline 10-14 years & 0.4 & 0.7 & 5 & 0.5 \\
\hline 15-19 years & 8.8 & 15.8 & 107 & 10.8 \\
\hline 20-24 years & 16.6 & 20.1 & 175 & 17.6 \\
\hline 25-29 years & 15.8 & 10.8 & 144 & 14.4 \\
\hline 30-34 years & 9.8 & 14.0 & 109 & 11.0 \\
\hline 35-39 years & 10.6 & 9.3 & 103 & 10.3 \\
\hline 40-44 years & 8.4 & 9.7 & 87 & 8.7 \\
\hline 45-49 years & 8.2 & 6.5 & 77 & 7.7 \\
\hline 50-54 years & 8.7 & 7.5 & 83 & 8.3 \\
\hline 55-59 years & 8.1 & 5.4 & 73 & 7.3 \\
\hline $60-64$ years & 1.1 & 0.4 & 9 & 0.9 \\
\hline 65 and above & 0.7 & 0.0 & 5 & 0.5 \\
\hline Not mentioned & 2.0 & 0.0 & 20 & 2.0 \\
\hline Total & 100.0 & 100.0 & 995 & 100.0 \\
\hline
\end{tabular}

The above table 2 depicts that the percent of TB patients were comparatively more between the age group 20 to 39 years. The age above 65 years have less TB problem and 2 percent of the patients have not mentioned of their status.

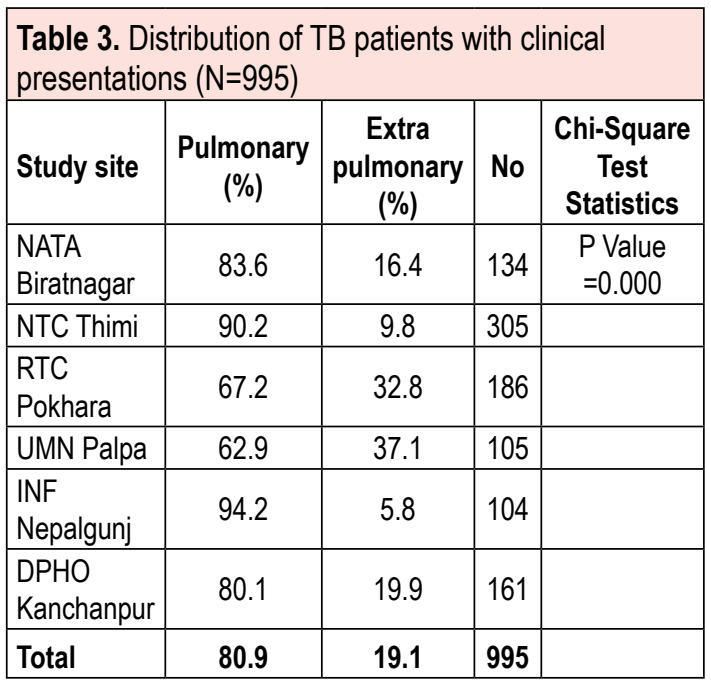

Above table 3 shows that among total TB patients tested for HIV, 80.9 percent were pulmonary positive and rest 19.1 percent were extra pulmonary TB patients. The finding of the above table is statistically significant.

\begin{tabular}{|c|c|c|c|c|}
\hline Sex & $\begin{array}{l}\text { Positive } \\
(\%)\end{array}$ & $\begin{array}{l}\text { Negative } \\
(\%)\end{array}$ & $\mathrm{N}=995$ & $\begin{array}{c}\text { Chi-Square } \\
\text { test Statistics }\end{array}$ \\
\hline Male & 2.8 & 97.2 & 716 & $P$ Value $=0.209$ \\
\hline Female & 1.4 & 98.6 & 279 & \\
\hline Total & 2.4 & 97.6 & 995 & \\
\hline
\end{tabular}

From above table 4 male female analysis of HIV status among 995 tested TB patients can be observed. All 995 (male and female) TB patients opted out HIV testing during the surveillance period because eligibility criteria to part in surveillance for HIV testing is all consenting newly registered TB patients (smear positive, smear negative and extra-pulmonary) $>15$ years of age. Among the total 716 male TB patients tested for HIV, 2.8 percent were HIV positive whereas among total 279 female tested TB patients, 1.4 percent were HIV positive. All HIV positive TB patients were linked with National AIDS Control Programme and enrolled in ART to receive care and support. 


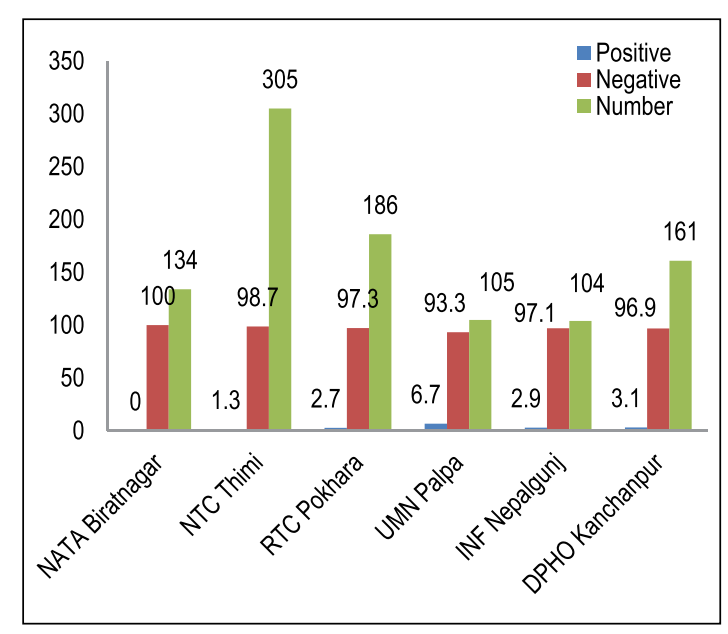

Figure 1. Knowledge among the students regarding HIV/ AIDS

The above figure 1 showed that prevalence of HIV among tested TB patients was found high in UMN, Palpa (6.7) followed by 3.1, 2.9, 2.7 and 1.3 in DPHO, Kanchanpur, INF, Nepalguni, RTC, Pokhara and NTC Thimi, Bhaktapur respectively and not a single case found in NATA, Biratnagar. 2.4 percent of tested TB patients were found HIV positive whereas 97.6 percent remained HIV negative.

\begin{tabular}{|c|c|c|c|}
\hline Age Group & Positive \% & Negative $\%$ & Count \\
\hline $10-14$ years & 0.0 & 100.0 & 5 \\
\hline $15-19$ years & 0.0 & 100.0 & 107 \\
\hline 20-24 years & 1.1 & 98.9 & 175 \\
\hline $25-29$ years & 0.7 & 99.3 & 143 \\
\hline 30- 34 years & 2.8 & 97.2 & 109 \\
\hline 35-39 years & 7.8 & 92.2 & 102 \\
\hline $40-44$ years & 4.6 & 95.4 & 87 \\
\hline $45-49$ years & 1.3 & 98.7 & 77 \\
\hline $50-54$ years & 3.6 & 96.4 & 83 \\
\hline $55-59$ years & 2.7 & 97.3 & 73 \\
\hline $60-64$ years & 0.0 & 100.0 & 9 \\
\hline 65 and above & 0.0 & 100.0 & 5 \\
\hline Not mentioned & 0.0 & 100.0 & 20 \\
\hline Total & 2.4 & 97.6 & 995 \\
\hline
\end{tabular}

The table 5 shows the age group wise distribution of TB patients who have been tested and found HIV positive. It was found that 7.8 percent of the HIV positive among tested TB patients were between age group of 35-39 years which is again followed by $4.6 \%, 3.6 \%$ and $2.8 \%$ among the age group of 40-44 years, 50-54 years and 30-34 years age group respectively. The prevalence of HIV among tested TB patients was lowest between age group of 20-24 years and not a single case of HIV positive found in the age group of 10-19 years and above 60 years.

Table 6. Sentinel sites wise post test counselling status among HIV tested TB patients

\begin{tabular}{|l|c|c|c|}
\hline Sentinel Sites & Yes (\%) & No (\%) & Number \\
\hline NATA Biratnagar & 92.5 & 7.5 & 134 \\
\hline NTC Thimi & 2.3 & 97.7 & 305 \\
\hline RTC Pokhara & 81.7 & 18.3 & 186 \\
\hline UMN Palpa & 15.2 & 84.8 & 105 \\
\hline INF Nepalgunj & 100.0 & 0.0 & 104 \\
\hline DPHO Kanchanpur & 100.0 & 0.0 & 161 \\
\hline Total & $\mathbf{5 6 . 7}$ & $\mathbf{4 3 . 3}$ & $\mathbf{9 9 5}$ \\
\hline
\end{tabular}

From above table 6 , it is evident that more than half $(56.7 \%)$ of the HIV tested TB patients received the post test counselling whereas more than twofifth $(43.3 \%)$ of the HIV tested TB patients didn't receive post test counselling. Cent percent of the HIV tested TB patients had received post test in INF Nepalgunj and DPHO Kanchanpur and lowest in NTC (2.3\%) followed by UMN Palpa (15.2\%). Counselling is crucial aspect of the HIV testing, thus pre and post test counselling is very much important to incorporate in HIV testing programme. Therefore the future interventions is this areas must give due importance for HIV testing programme.

\section{DISCUSSION}

HIV co-infection among TB patients is well recognized as a major public health problem worldwide. HIVIAIDS pandemic has caused a resurgence of $T B$, resulting in increased morbidity and mortality worldwide. ${ }^{5}$ From the epidemiological point of view, our TB/HIV patients differed in some respects from those present in other parts of the world.

In this study, the prevalence of HIV co-infection among TB patients was $2.4 \%$. However, this finding is by far higher than that of studies reported from central European countries (0-1\%). In England, the prevalence of HIV co-infection among TB patients rose from $5 \%$ in 2000 to $8 \%$ in 2005, with a peak at $9 \%$ in 2003-2004. These figures are at the higher end of what is observed in Europe. France, Iceland and Portugal (11-15\%) had higher co-infection levels. A rise in co-infection levels was seen in Estonia, Latvia, Lithuania, the UK and 
Belgium, while decreases were seen in Spain and Portugal. ${ }^{6}$ The findings of this study is slightly lower than that of reported from India (4.85\%) in 2007. ${ }^{7}$ The burden was higher in countries reporting high levels of HIV testing and countries with a higher HIV burden. Similar recent studies conducted in northwest Ethiopia (7.5\%), and the 2012 WHO report for Ethiopia (8.0\%). ${ }^{8}$ However, according to the 2012 WHO report, prevalence of HIV coinfection among TB patients (13.0\%). ${ }^{9}$

Sentinel site wise prevalence of HIV among tested TB patients was found high in UMN, Palpa (6.7) followed by 3.1, 2.9, 2.7 and 1.3 in DPHO, Kanchanpur, INF, Nepalgunj, RTC, Pokhara and National Tuberculosis Centre (NTC) Thimi, Bhaktapur respectively. This study is consistent with the findings of other studies i.e., the rate of HIV infection in TB patients was ranging from $8.3 \%$ (in Silte zone) to $35.3 \%$ (in South Omo zone). ${ }^{10}$ This high prevalence of HIV co-infection among TB patients in the study area signifies the urgent need for programmatic revision, strengthening the health system infrastructure, staff capacity building, increasing public awareness, decreasing social and perceived stigma associated with TB and HIV and innovating for patient-friendly and cultural sensitive intervention approaches. ${ }^{11}$

Male female analysis of HIV status among tested TB patients indicates that $2.8 \%$ male and $1.4 \%$ female were HIV positive. Other studies support this finding (Dagnra AY et al., 2011; Alaneme Uzoma et al., 2008-9). ${ }^{12,13}$ Currently there has been a conflicting report of occurrence of TB/HIV coinfection with regards to sex. For instance Adji et al. in Cameron showed that women had significantly more TB/HIV co-infected than men $(42 \%)^{14}$ However Demissie et al. in Ethiopia indicated that TB/HIV co-infection did not have any significance difference with sex. ${ }^{15}$

In this study, 7.8 percent of the HIV positive among tested TB patients were between age group of 3539 years followed by $4.6 \%, 3.6 \%$ and $2.8 \%$ among the age group of $40-44$ years, $50-54$ years and 30 34 years age group respectively. The prevalence of HIV among tested TB patients was lowest between age group of $20-24$ years. This findings is similar to other study i.e., the highest prevalence of co-infection was recorded among aged 3039 (Alaneme Uzoma et al., 2008-9) and another indicated the age group of $15-39$ years. ${ }^{16}$
This study also depicted similar findings which is consistent with the findings of other studies (Pennap et al., 2010; Kamenju et al., 2011). ${ }^{17,18}$ This age prevalence of HIV co-infection among TB patients probably reflects the age-specific prevalence of HIV in the community. This may be related to patients' being in a sexually active age group in which both TB and HIV prevail most (Tessema et al., 2009; Berhe et al., 2012). ${ }^{19,20}$ The other possible explanation for this may be their increased family, organizational, and societal responsibilities as people in this age group involve themselves in various extraneous daily activities in order to win the socio-economic hardship which increases the frequency of their contact with other patients in their society.

\section{CONCLUSION}

Regarding type of TB patients tested for HIV, fourfifth $(80.9 \%)$ were pulmonary positive and rest less than one-fifth $(19.1 \%)$ percent were diagnosed as extra pulmonary TB patients. The percent of TB patients was comparatively more between the age group 20 to 39 years. Study revealed that 2.4 percent prevalence of HIV found among tested TB patients whereas 97.6 percent found HIV negative.

Significant proportion $(7.8 \%)$ of the TB patients found HIV positive was between age group of 35-39 years and lowest between age group of 2024 years. Therefore, it is important to implement targeted interventions in the age group between 30-55 years age group.

Majority (56.7\%) of the HIV tested TB patients received the post test counselling whereas less than half $(43.3 \%)$ of the HIV tested TB patients were didn't received. Thus, it is concluded that post test counselling interventions should be scaled up in all the sentinel sites to ensure that HIV positive TB patients receive proper counselling.

Thus, the prevalence HIV co-infection among TB patients was high. This calls for emergency response through strengthening the $\mathrm{TB}$ and HIV collaborative activities, decentralizing the diagnostic and treatment centers to reach the periphery, providing women and young age targeted interventions, initiating early diagnosis and treatment, improving nutritional supplementation to boost immunity, and providing prophylaxis to prevent opportunistic infections. 


\section{REFERENCES}

1. National Tuberculosis Program, Nepal - General Manual - Third Edition 2012

2. Tuberculosis Control in the South-East Asia Region - 2012 WHO Report - www.searo.who.int/tb

3. Ministry of Health, Government of Ethiopia. July 2005. TB/HIV Implementation Guidelines.

4. Implementing collaborative TB/HIV activities A programmatic Guideline 2012, published by International Union against Tuberculosis and Lung Disease.

5. Sharma SK, Mohan A, Kadhiravan T. HIVTB co-infection: Epidemiology, diagnosis and management. Ind J Med Res. 2005;121:550-67.

6. M E Kruijshaar et al; TB-HIV co-infection: how does the UK compare to Europe? Thorax 2010;65:A150 doi:10.1136/ thx.2010.151043.21

7. TB India. RNTCP status report. Available from: http://wwwtbcindiaorg/pdfs/TB\%20India\%20 2010 [Last accessed on 2010 Apr 24]

8. Wondimeneh Y, Muluye D, Belyhun S Prevalence of pulmonary tuberculosis and immunological profile of HIV co-infected patients in Northwest Ethiopia. BMC Research Notes 2012;5:331.

9. WHO Global Tuberculosis Control, Geneva 2012.

10. Daniel G Datiko, Mohammed A Yassin, Luelseged T Chekol, Lopisso E Kabeto and Bernt Lindtjørn: The rate of TB-HIV co-infection depends on the prevalence of HIV infection in a community. BMC Public Health 2008;8:266doi:10.1 186/1471-24588-266.

11. Deribew A, Hailemichael $Y$, Tesfaye $M$, Desalegn $D$, Wogi A, Daba S. The synergy between TB and HIV co-infection on perceived stigma in Ethiopia. BMC Research Notes 2010;3:249. Doi: 10.1186/17560500-3-249.
12. Dagnra AY, Adjoh K, et al Prevalence of HIV-TB coinfection and impact of HIV infection on pulmonary tuberculosis outcome in Togo. 2011;104:342-6.doi: 10.1007/s13149-010-0079-3. Epub 2010 Sep 4.

13. Alaneme Uzoma, Aki Shadrack, Akata Nkechi, Akande Ifeoluwa: Prevalence and sociodemographic characteristics of TB/HIV co-infection using chest unit, UNTH, as a case study College of Medicine, University of Nigeria, Enugu Campus, Nigeria 2008-2009.

14. Pefura Yone EW, Kuaban C, Kengne AP HIV testing. HIV status and outcomes of treatment for tuberculosis in a major diagnosis and treatment centre in Yaounde, Cameroon: a retrospective cohort study. BMC Infect Dis 2012;12:190.

15. Demissie M, Lindtjørn B, Tegbaru B. Human immunodeficiency virus (HIV) infection in tuberculosis patients in Addis Ababa. Ethiop. J. Health Dev 2000;14:277-82.

16. Sebsibe Tadesse, Takele Tadesse. HIV co-infection among tuberculosis patients in Dabat, northwest Ethiopia 2013;5:29-32

17. Pennap G, Makpa S, Ogbu S. The Prevalence of HIVIAIDS among tuberculosis patients In a Tuberculosis/Leprosy Referral Center in Alushi, Nasarawa State, Nigeria. Int. J. Epidemi 2010;8:10.

18. Kamenju P, Aboud S. Tuberculosis - HIV coinfection among patients admitted at Muhimbili National Hospital in Dares Salaam, Tanzania. Tanzan. J. Health Res. 2011;13:25-31.

19. Tessema B, MucheA, BekeleA, Reissig D, Emmrich $F$, Sack U. Treatment outcome of tuberculosis patients at Gondar University Teaching Hospital, Northwest Ethiopia: a five-year retrospective study. BMC Public Health 2009;9:371.

20. Berhe G, Enquselassie F, Aseffa. A Treatment outcome of smear positive pulmonary tuberculosis patients in Tigray Region, Northern Ethiopia. BMC Public Health. 2012;12:537. 